\title{
An Incentive Theory of Matching
}

Alessio J. G. Brown

Christian Merkl

Dennis J. Snower

April 2009 


\title{
An Incentive Theory of Matching
}

\author{
Alessio J. G. Brown \\ Kiel Institute for the World Economy \\ Christian Merkl \\ Kiel Institute for the World Economy \\ and IZA \\ Dennis J. Snower \\ Kiel Institute for the World Economy \\ and IZA
}

Discussion Paper No. 4145

April 2009

IZA

P.O. Box 7240

53072 Bonn

Germany

Phone: +49-228-3894-0

Fax: +49-228-3894-180

E-mail: iza@iza.org

\begin{abstract}
Any opinions expressed here are those of the author(s) and not those of IZA. Research published in this series may include views on policy, but the institute itself takes no institutional policy positions.

The Institute for the Study of Labor (IZA) in Bonn is a local and virtual international research center and a place of communication between science, politics and business. IZA is an independent nonprofit organization supported by Deutsche Post Foundation. The center is associated with the University of Bonn and offers a stimulating research environment through its international network, workshops and conferences, data service, project support, research visits and doctoral program. IZA engages in (i) original and internationally competitive research in all fields of labor economics, (ii) development of policy concepts, and (iii) dissemination of research results and concepts to the interested public.
\end{abstract}

IZA Discussion Papers often represent preliminary work and are circulated to encourage discussion. Citation of such a paper should account for its provisional character. A revised version may be available directly from the author. 
IZA Discussion Paper No. 4145

April 2009

\section{ABSTRACT}

\section{An Incentive Theory of Matching}

This paper presents a theory explaining the labor market matching process through microeconomic incentives. There are heterogeneous variations in the characteristics of workers and jobs, and firms face adjustment costs in responding to these variations. Matches and separations are described through firms' job offer and firing decisions and workers' job acceptance and quit decisions. This approach obviates the need for a matching function. On this theoretical basis, we argue that the matching function is vulnerable to the Lucas critique. Our calibrated model for the U.S. economy can account for important empirical regularities that the conventional matching model cannot.

JEL Classification: E24, E32, J63, J64

Keywords: matching, incentives, adjustment costs, unemployment, employment, quits, firing, job offers, job acceptance

Corresponding author:

Christian Merkl

Kiel Institute for the World Economy

Düsternbrooker Weg 120

24105 Kiel

Germany

E-mail: christian.merkl@ifw-kiel.de 


\section{Introduction}

The literature on search and matching in the labor market rests heavily on the assumption of a stable matching function (Mortensen and Pissarides, 1994). According to Pissarides (2000, p. 3-4), the matching function aims to summarize "heterogeneities, frictions and information imperfections" and represent "the implications of the costly trading process without the need to make the heterogeneities and the other features that give rise to it explicit." Various authors (e.g. Lagos (2000)) have noted that policies which affect labor market heterogeneities (e.g. retraining programs), frictions (e.g. job counselling) and information imperfections (e.g. job exchanges) may naturally be expected to influence the matching function. In short, there is no reason to believe that the matching function is invariant with respect to labor market policies that are designed to improve the matching process. ${ }^{1}$ Beyond that, there are a wide variety of labor and macroeconomic shocks (e.g. information technology and productivity shocks, variations in hiring, training and firing costs) that also affect the matching process and thereby can influence the matching function. Under these various circumstances, the matching function may run afoul of the Lucas critique.

This paper addresses this problem by proposing a new approach to the matching process that obviates the need for a matching function. Alternatively, this approach can also be viewed as an attempt to provide more insight into the determinants of labor market matching. Our analysis suggests that the matching function is not stable with respect to policies that affect matching frictions and, beyond that, not stable with respect to various macroeconomic shocks, calling into question the usefulness of assuming stable matching functions in macroeconomic models. On this account, we argue that in analyzing the effects of many labor policies and other macroeconomic shocks, the matching function may be relinquished in favor of a choice-theoretic framework that covers the microeconomic decisions underlying the matching process.

This paper provides a framework of this sort. We present two simple models of heterogeneous variations in the characteristics workers and jobs, combined with adjustment costs in responding to these variations. In this context, we derive the job offer and firing decisions of firms and the job acceptance and quit decisions of workers, and show how these decisions generate labor market matches and separations. Needless to say, we make no attempt to be comprehensive in covering the wide variety of frictions that are prevalent in labor markets, but we believe that our analysis is sufficient to clarify a general modeling strategy for moving beyond the matching function and to indicate how this strategy could be extended

\footnotetext{
${ }^{1}$ Several empirical studies indicate instabilities of the matching function. Very often a negative time trend is found when estimating the search and matching function, thus casting doubt on the stability through time (Blanchard and Diamond (1989) for the United States, and Fahr and Sunde (2001, 2004) for Germany).
} 
to other areas. Our analysis may be called an incentive theory of matching, since it enables us to explain the microeconomic decisions relevant to the matching process in terms of the incentives that economic agents face.

We calibrate our incentive model for the U.S. economy and show that it can account for some important empirical regularities that the conventional matching model cannot. First, our model generates labor market volatilities that are close to what can be found in the empirical data, specifically for the unemployment rate, the job finding rate and the separation rate. This is remarkable, as we do not rely on any type of real wage rigidity. Instead, our calibration permits us to replicate the stylized fact that wages are as volatile as productivity (see, for example, Hornstein et al., 2005). The standard calibration of the conventional matching model ${ }^{2}$ is unable to generate these high volatilities of labor market variables (see Shimer, 2005). Second, it generates a strong negative correlation between the job finding rate and the unemployment rate. And third, it can account for a strong negative correlation between job creation and job destruction. The standard calibrations of the matching model, with endogenous job destruction (see Krause and Lubik, 2007), cannot account for these last two stylized facts. ${ }^{3}$

The rest of this paper is organized as follows. Section 2 covers the conceptual issues underlying our approach to matching. Section 3 sets the stage by presenting a particularly simple and transparent incentive model of matching. Section 4 presents an extended incentive model. Section 5 discusses the calibration strategy. Section 6 presents the numerical results and Section 7 concludes.

\section{Conceptual Issues}

The matching function is aptly rationalized by Petrongolo and Pissarides (2001, p. 390): "The attraction of the matching function is that it enables the modeling of frictions in otherwise conventional models, with a minimum of added complexity. Frictions derive from information imperfections about potential trading partners, heterogeneities, the absence of perfect insurance markets, slow mobility, congestion from large numbers, and other similar

\footnotetext{
${ }^{2}$ The "standard" calibration of the model excludes rigid wages and small surplus calibrations. Although the rigid wage version of the search and matching model can also generate higher volatilities (Hall, 2005), it implies that counterfactual prediction that wages are acyclical. Thus we do not make this assumption here. We also do not rely on Hagedorn and Manvoskii's (2008) small surplus calibration, in which the average unemployed worker is basically indifferent between working and not working. In the calibrated version of our model, the current period's utility of an average unemployed is only about $80 \%$ of the utility of an employed.

${ }^{3}$ The search and matching model with exogenous job destruction actually has a strong negative correlation between the job finding rate and the unemployment (see Shimer, 2005). However, there is an intensive debate in the literature whether separations are exogenous or not (see, for example, Hall, 2006, and Fujita and Ramey, 2009, for opposing views). Separations are endogenous in our analysis.
} 
factors." Furthermore, they explain "the matching function summarizes a trading technology between agents who place advertisements, read newspapers and magazines, go to employment agencies, and mobilize local networks that eventually bring them together into productive matches. The key idea is that this complicated exchange process is summarized by a wellbehaved function that gives the number of jobs formed at any moment in time in terms of the number of workers looking for jobs, the number of firms looking for workers, and a small number of other variables" (p. 391).

Shimer (2007, p. 1074) makes an insightful distinction between search and mismatch: "According to search theory, unemployed workers have left their old jobs and are actively searching for a new employer. In contrast, his dynamic model of mismatch emphasizes that unemployed workers are attached to an occupation and a geographic location in which jobs are currently scarce. Mismatch is a theory of former steel workers remaining near a closed plant in the hope that it reopens. Search ... is a theory of former steel workers moving to a new city to look for positions as nurses." While this distinction is undoubtedly important, it is worth emphasizing that adjustment costs are responsible for both mismatch and search. The reason that the former steel workers remain near the closed plant is that the cost of adjusting to another job (net of the expected benefits) is greater than the cost of waiting for the plant to open (again net of the expected benefits). Moreover, if the former steel workers can't find jobs as nurses despite the existence of nursing vacancies, then the reason is that either it was too costly for the workers to find the available vacancies or it was too costly for the employers to find the available workers. So, under both mismatch and search, unemployed workers and vacancies coexist because it is too costly to fill the vacancies with the unemployed workers. Otherwise, obviously, the match would have been made. Under mismatch, the costs are frequently large and persistent, whereas under search they are often small and transient; but the fact remains that adjustment costs are responsible for the friction in both cases.

Our point of departure is to investigate the role of these adjustment costs as a source of labor market frictions. The adjustment costs of course come in many guises. Some are costs of geographic and occupational mobility (as in Shimer's analysis); others are costs of obtaining the relevant information (the standard search costs, e.g. costs of advertising, monitoring, screening).

The most straightforward way to account for the coexistence of employed and unemployed workers alongside filled and unfilled jobs is by invoking heterogeneities of workers or jobs. Some workers are offered employment because they are sufficiently profitable (net of the firm's adjustment costs); others remain unemployed because their are insufficiently profitable (under these adjustment costs). These differences may arise since workers differ in terms 
of their productivities, their costs of being identified as searching and employable, their relocation and training costs, etc. In the same vein, some job offers are accepted because they offer sufficient remuneration (net of the potential job holder's adjustment costs); others are rejected because they are not sufficiently remunerative (net of adjustment costs). These differences may exist because jobs differ in terms of job productivities (due to capital and technologies attached to the job), costs of being identified as vacant, etc. Our analysis focuses on such heterogeneities.

In many conventional search models that use a matching function, workers and jobs are treated as if each group were homogeneous and randomly matched. We do not wish to imply that random selection among homogeneous workers and homogeneous jobs does not occur; and when it does, matching functions come into their own. ${ }^{4}$ But we do suggest that random selection occurs far more rarely in practice than the conventional search theory assumes. Instead, the random selection of workers and vacancies implicitly described by matching functions is largely a short-hand that economists use for dealing with their own imperfect information. Workers who look indistinguishable to the economists are rarely indistinguishable in terms of all the characteristics relevant for job acquisition and thus firms' choices among workers is rarely completely random. Similarly for vacancies. Heterogeneities of workers and jobs naturally play a pervasive role in explaining why some workers find jobs and others do not and some vacancies are filled while others remain vacant. It is these heterogeneities, characterized in a simple way, on which our analysis focuses attention.

While various other authors have modeled the matching process without resorting to a matching function (e.g. Hall (1977), Lagos (2000), Shimer (2007) and others), our analysis explicitly focuses on two-sided search (i.e. search by both workers and firms at the same time) and an optimizing framework that makes a matching function superfluous. Due to our focus on heterogeneities and adjustment costs, it is not necessary for our analysis to make a sharp distinction between search and mismatch. Our analysis is meant to cover both phenomena, depending on how we choose to interpret the nature of the heterogeneities and adjustment costs. In this context, as noted above, we show that our analysis can explain various stylized facts that are not accounted for in the convential search and matching literature.

\section{A Simple, Illustrative Model}

To set the stage, we begin by constructing a particularly simple model of the incentive theory of matching, based on heterogeneous jobs and workers. Our model has the following sequence

\footnotetext{
${ }^{4}$ Even when a worker selects jobs with the same advertised characteristics in a newspaper, the selection may not be random due to perceived job heterogeneities: some vacancy adds are easier to spot than others.
} 
of labor market decisions. First, the realized values of the shocks are revealed. Second, the firms make their hiring and firing decisions and the households make their job acceptance and refusal decisions, of course taking the wage as given. Unemployed workers search for jobs; employed workers do not.

For simplicity, we will not consider vacancies in our model. While it is of course possible to include them (as illustrated briefly below), doing so would complicate our analysis without amplifying the basic point of this paper, namely, to describe the matching process without need for a matching function, which is vulnerable to the Lucas critique. Beyond that, it is worth noting that vacancy data is the Achilles' heal of conventional empirical matching models. For U.S. long time series, we have only a very rough proxy for vacancies, namely, the Conference Board help-wanted advertising index, measuring the number of help-wanted ads in 51 major newspapers. Over the past decade, this index shows a clear downward trend (adjusting for the business cycle), which may well be due to internet advertising. Although an internet advertising index exists, it is far from clear how this index can be made comparable to the newspaper index. Moreover, while the Conference Board advertising index and the JOLTS survey on vacanices exhibit similar dynamics for the limited sample periods in which comparable data sets are available (Shimer (2005)), it appears, surprisingly, that the number of vacancies (as defined by the JOLTS survey) is consistently and substantially smaller than the number of new hires! There are two obvious reasons why this should be so, both highlighting weakenesses of vacancies data: (i) Only a fraction of the jobs that get filled are preceeded by vacancy postings. (The matching function has nothing to say about the many hires that occur without formal advertising.) (ii) The JOLTS survey, like all other surveys, ignores high-frequency vacancy movements. In particular, JOLTS measures end-of-month reported job openings, not job openings that get filled before the month is over. Overall, such considerations indicate that vacancy data is much less reliable than the other data (e.g. unemployment rates, productivity) used in conventional empirical matching models. On account of this as well as analytical simplicity, our incentive model will not cover vacancies.

To keep our analysis as simple as possible, we shall assume in this section that the real wage $w$ is exogenously given. It is easy to extend the model to include wage bargaining, along the lines usually presented in the standard matching models, but this would complicate our analysis without adding new insights. On this account, we forego a model of wage determination in this section. The wage will, however, be endogenized in the extended model of the next section.

Furthermore, to provide a maximally transparent comparison of our incentive model and the standard matching model, let us assume that workers and firms are myopic (i.e. their 
rates of time discount are 100\%). This assumption will be relaxed later.

\subsection{The Firm's Behavior}

We assume that the profit generated by a particular worker at a particular job is subject to a random shock $\varepsilon$, which is meant to capture idiosyncratic variations in workers' suitability for the available jobs. For example, workers in a particular skill group and sector may exhibit heterogeneous profitabilities due to random variations in their state of health, levels of concentration, and mobility costs, or to random variations in firms' operating costs, screening, training, and monitoring costs, and so on. In short, the random shock $\varepsilon$ is a short-hand for workplace heterogeneities. It is iid across workers, with a stable probability density function $G_{\varepsilon}(\varepsilon)$, known to the firm. ${ }^{5}$ Let the corresponding cumulative distribution be $C_{\varepsilon}(\varepsilon)$. The period of analysis is equal to the period between successive realizations of $\varepsilon$.

The average productivity of each worker is $a$, a positive constant. The hiring cost $h$ per worker is a constant. The profit generated by an entrant (a newly hired worker) is

$$
\pi^{E}=a-\varepsilon-w-h
$$

where the superscript "E" stands for "entrant" and $w$ is the real wage.

The firm's "job offer incentive" (its payoff from hiring a worker) is the difference between its gross profit ${ }^{6}$ from hiring an entrant worker $(a-w-h)$ and its profit from not doing (namely, zero):

$$
\nu^{E}=a-w-h
$$

The firm offers this job to a worker whenever that worker generates positive profit: $\varepsilon<\nu^{E}$. Thus the job offer rate is

$$
\eta=C_{\varepsilon}\left(\nu^{E}\right)
$$

The firm's "retention incentive" (its payoff from retaining a worker) is the difference between its gross profit from retaining a worker is $(a-w)$ and the (negative) profit from firing that worker:

$$
\nu^{I}=a-w+f
$$

where the superscript " $I$ " stands for the incumbent employee who has been retained, and $f$ is the firing cost per worker, assumed constant. The firm with a filled job will fire an

\footnotetext{
${ }^{5}$ Our analysis can of course be extended straightforwardly to shocks with AR and MA components. For mobility costs, the shocks are often serially correlated in practice.

${ }^{6}$ This "gross" profit is the expected profit generated by hiring an unemployed worker, without taking the operating cost into account.
} 
incumbent worker whenever she generates negative profit: $\varepsilon>\nu^{I}$. Thus the firing rate is:

$$
\phi=1-C_{\varepsilon}\left(\nu^{I}\right) .
$$

Note that due to the hiring and firing costs, the retention incentive exceeds the job offer incentive $\left(\nu^{I}>\nu^{E}\right)$ and thus the retention rate exceeds the job offer rate $((1-\phi)>\eta)$.

\subsection{The Worker's Behavior}

The worker faces a discrete choice of whether or not to work. If she works, her disutility of work effort is $e$, which is a random variable with a stable probability density function $G_{e}(e)$, known to the worker. The corresponding cumulative distribution is $C_{e}(e)$. The random variable captures heterogeneities in the disagreeability of work, due to such factors as temporary variations in health, moods, idiosyncratic reactions to particular workplaces, and personal circumstances. If the worker does not work, her utility is $b$ (a constant). Her utility is linear in consumption and work effort. ${ }^{7}$ She consumes all her income. Thus the utility of an employed worker is $V^{N}=w-e$, and the utility of an unemployed worker is $V^{U}=b$.

A worker's "work incentive" (her payoff from choosing to work) is the difference between her gross utility from working $(w)$ and her utility from not working $(b)$ :

$$
\iota=(w-b) .
$$

Assuming that $w>b$ and letting $E(e)=0$, all unemployed workers have an ex ante incentive to seek work.

An unemployed worker will accept a job offer whenever $e<\iota$. This means that the job acceptance rate is

$$
\alpha=C_{e}(\iota) .
$$

Along the same lines, an employed worker will decide to quit when $e>\iota$. This means that the quit rate is

$$
\chi=1-C_{e}(\iota) .
$$

Note that, for simplicity, we have assumed that the job acceptance rate is identical to the job retention rate $(\alpha=1-\chi)$. When unemployed workers face costs of adjusting to

\footnotetext{
${ }^{7}$ Observe that on the firm's side, we distinguish between entrants $(E)$ and incumbent workers $(I)$; whereas on the workers' side, we distinguish between employed $(N)$ and unemployed $(U)$ workers. The rationale for these two distinctions is that the firm can hire two types of workers (entrants and incumbents), whereas the worker can be in two states (employment and unemployment).
} 
employment (e.g. buying a car to get to work, or psychic costs of changing one's daily routine) or when employed workers face costs of adjusting to unemployment (e.g. building networks of friends with potential job contacts, psychic costs of adjusting to joblessness), then the job acceptance rate would fall short of the job retention rate. ${ }^{8}$

\subsection{Employment}

An unemployed worker gets a job when two conditions are fulfilled: (i) she receives a job offer and (ii) she accepts that offer. Thus the match probability $(\mu)$ is the product of the job offer rate $(\eta)$ and the job acceptance rate $(\alpha)$ :

$$
\mu=\eta \alpha
$$

Consequently the number of unemployed workers who get jobs in period $t$ is $\mu U_{-1}$, where $U_{-1}$ is the number of unemployed in the previous period. ${ }^{9}$

An employee separates from her job when at least one of two conditions is satisfied: (i) she is fired or (ii) she quits. Thus the separation probability is

$$
\sigma=\phi+\chi-\phi \chi
$$

This implies that the number of employed who separate from their jobs in period $t$ is $\sigma N_{-1}$, where $N_{-1}$ is the number of employed in the previous period.

The change in employment is $\Delta N=N-N_{-1}=\mu U_{-1}-\sigma N_{-1}$. The labor force $L$ is assumed constant. Thus $U=L-N$ and employment may be described by

$$
N=\mu U_{-1}+(1-\sigma) N_{-1}=\mu L+(1-\mu-\sigma) N_{-1}
$$

Expressing the equation in terms of the employment rate, $n=N / L$, yields the following employment equation:

$$
n=\mu+(1-\mu-\sigma) n_{-1} .
$$

Although we have not included vacancies in our model - since doing so would complicate our analysis without contributing substantially to our main message - it is worth noting that

\footnotetext{
${ }^{8}$ Specifically, for example, the unemployed worker's job acceptance incentive could be expressed as $\iota^{U}=$ $w-b-\xi^{U}$, where $\xi^{U}$ is the cost of adjusting to employment, and the incumbent worker's job retention incentive could be expressed as $\iota^{N}=w-b+\xi^{N}$, where $\xi^{N}$ is the cost of adjusting to unemployment. Then the job acceptance rate becomes $\alpha=C_{e}\left(\iota^{U}\right)$, the job retention rate becomes $C_{e}\left(\iota^{N}\right)$ so that the quit rate becomes $\chi=1-C_{e}\left(\iota^{N}\right)$.

${ }^{9}$ All other variables (without subscripts) refer to the current period.
} 
vacancies could be included straightforwardly as an instrument, whereby firms manipulate their employment adjustment costs. See Appendix A for a simple example.

\subsection{The Matching-Function Representation}

We now juxtapose the model above with its matching-function counterpart in order to investigate the stability of the matching function. For this purpose, let us assume that the model above describes the real world, and then let us ask how the behavior of this model can be replicated by a corresponding model containing a matching function. We will show that such replication cannot occur unless the matching function changes whenever the underlying parameters of the model change. These parameter changes include macroeconomic variables (such as productivity, $a$ ) and policy variables (such as unemployment benefits, underlying the parameter $b$ ). Thus, in this analytical context, the matching function runs afoul of the Lucas critique: policy analysis and comparative static prediction on the basis of a stable matching function would yield misleading results.

Naturally, the incentive model above is extremely simple, but it is precisely this simplicity that allows us to bring the Lucas critique of the matching function into sharp relief. Needless to say, the same critique can be formulated with respect to more complicated models (such as the one in the next section), since the underlying idea is quite general: For any given matching function - specified independently of the optimizing decisions relevant to the matching process - it is always possible to contruct a microfounded macro model that systematically fools this matching function. In this sense, the difficulty of the matching functions is analogous to that of expectation-generating mechanisms in traditional macro models that were incompatible with rational expectations.

Let the matching function be

$$
x=x(u, v)
$$

where $u$ is the unemployment rate and $v_{t}$ is the vacancy rate (number of vacant jobs relative to the labor force). This function satisfies the standard conditions: $x_{i}>0, x_{i i}<0, i=u, v$; $x(u, 0)=x(0, v)=0$; and there are constant returns to scale: $g x(u, v)=x(g u, g v)$ where $g$ is a positive constant.

Let $\theta=v / u$ denote labor market tightness, so that $q(\theta)=x(u / v, 1)$ is the probability that a job is matched with a worker, and $\theta q(\theta)$ is the probability that a worker is matched

by a job. Along the lines of the simple labor market matching models, we assume that jobs are destroyed at an exogenous rate $\lambda, 0<\lambda<1$. Then the change in the employment rate 
is $^{10} \Delta n=\theta q(\theta)\left(1-n_{-1}\right)-\lambda n_{-1}$, implying the following employment dynamics equation:

$$
n=\theta q(\theta)+(1-\theta q(\theta)-\lambda) n_{-1}
$$

Vacancies are posted until the expected profit is reduced to zero: $a-w=\frac{\kappa}{q(\theta)}$, where $\kappa$ is a vacancy posting cost, $\kappa / q(\theta)$ is the expected vacancy posting cost per worker. Expressing this zero-profit condition in terms of labor market tightness:

$$
\theta=g\left(\frac{\kappa}{a-w}\right)
$$

where $g=q^{-1}$.

The equilibrium employment rate $n$ is obtained by substituting the zero-profit condition (15) into the employment dynamics equation (14).

\subsection{Equivalence Conditions}

In order for the two models to be comparable, let the exogenous wage $w$ be identical in both models and suppose that the separation rate $\sigma$ in the incentive model is a constant equal to the job destruction rate $\lambda$ in the conventional matching model. Then the two models are observationally equivalent when $\theta q(\theta)+(1-\theta q(\theta)-\sigma) n_{t-1}=\mu+(1-\mu-\sigma) n_{t-1}$, so that

$$
\theta q(\theta)=\mu
$$

which we call the "equivalence condition." By implication,

$$
\frac{h}{a-w} g\left(\frac{h}{a-w}\right)=C_{\varepsilon}(a-w-h) C_{e}(w-b) .
$$

Differentiating this equation with respect to the wage $w$, we obtain:

$$
\frac{h}{(a-w)^{2}}\left(\frac{h}{a-w} g^{\prime}+g\right)=-C_{\varepsilon}^{\prime} C_{e}+C_{\varepsilon} C_{e}^{\prime} .
$$

Differentiating with respect to productivity a yields:

$$
\frac{h}{(a-w)^{2}}\left(\frac{h}{a-w} g^{\prime}+g\right)=C_{\varepsilon}^{\prime} C_{e} .
$$

\footnotetext{
${ }^{10}$ To keep this model comparable with our the simple incentive model above, we assume (without loss of generality) the same timing in both models. Matches are not destroyed in the match period and they become immediately productive.
} 
Finally, differentiating with respect to $b$,

$$
0=-C_{\varepsilon} C_{e}^{\prime} .
$$

It is clear that the conditions (18) - (20) are mutually exclusive: they cannot be fulfilled simultaneously. By assumption, the matching function is a shorthand for heterogeneities and frictions addressed explicitly in the incentive model of matching. It is a useful shorthand if it can be shown that (i) it is observationally equivalent to explicit model of the underlying heterogeneities and frictions and (ii) it is stable with respect to the macroeconomic and policy variables whose effects the matching model aims to analyze (to avoid the Lucas critique).

The comparison above indicates that these two conditions are not satisfied. The standard matching model cannot reproduce the labor market dynamics of the incentive model above. This non-equivalence is not a special case to be ascribed to the particular specification of the incentive model. It is easy to see that the reasoning above is applicable to a broad family of models.

The source of the non-equivalence is analogous to the non-equivalence of adaptiveexpectations and rational-expectatons macro models. Adaptive-expectations models were unable to reproduce the dynamics of rational-expectations models because, for any given function specifying adaptive expectations, it is always possible to find a hypothetically "true" stochastic generating process which produces predictable errors, that is, errors not reconcilable with rational expectations. Along the same lines, the comparison above makes clear that for any given matching function, it is always possible to find a hypothetically "true" model of the underlying heterogeneities and frictions which produces labor market dynamics that cannot be replicated through the matching function. Just as an expectations generating mechanism that is specified a priori (independently of the underlying macro model) is not a reliable tool for investigating the influence of macro policy, so a matching function that is specified a priori is also not a reliable tool to explore the influence of labor market policy. The same can be said regarding the influence of other macro and labor parameters.

Alternatively, we can say that the matching function is not stable with respect to the parameters whose influence the matching models are meant to analyze. If the incentive model above is assumed to be the "true" model of the labor market, then the standard matching model can reproduce the "true" employment effects of variations in all the relevant parameters - the wage $w$, productivity $a$, the hiring cost $h$, or the leisure utility $b$ - only if we assume that the matching function is modified whenever these parameters are changed. This instability of the matching function makes it an inappropriate tool for investigating the effectiveness of policy changes or macroeconomic fluctuations. 
Although the simple model above is useful to examine why the matching function is subject to the Lucas critique, we now need to relax several restrictive assumptions of the incentive model above - that households and firms are myopic, wages are exogenous, and productivity is constant - in order to examine the relative performance of the incentive model and the standard matching model in accounting for well-known stylized facts. In the context of conventional calibrations, we will show that the incentive model fares better than the standard matching model in reproducing the volatilities of major labor market variables.

\section{An Extended Incentive Model}

We now extend the simple model above by

- including aggregate risk: the average aggregate productivity parameter $a$ is now subject to random productivity shocks;

- allowing for rates of time discount that are less than $100 \%$, so that workers and firms become intertemporal optimizers and

- introducing wage determination through bargaining.

The first extension enables us to simulate productivity shocks as done in Hall (2005), Shimer (2005) and numerous other papers and to make our framework quantitatively comparable to the matching theory. The second and third extensions provide a richer depiction of the determinants of employment and wages.

In this context, the new sequence of decisions may be summarized as follows. First, the aggregate productivity shock and the idiosyncratic shocks are revealed. Second, the wage is set through bargaining. Third, the firms make their hiring and firing decisions and the households make their job acceptance and refusal decisions, taking the wage and the realization of the aggregate and idiosyncratic shocks as given.

\subsection{The Firm's Behavior}

Since the firm is not myopic in this model, its hiring and firing decisions depend on its expected profits not only in the current time period, but also in future time periods. 


\subsubsection{The Firing Decision}

The expected present value of profit generated by an incumbent employee, after the random profitability term $\varepsilon_{t}$ is observed, is ${ }^{11}$

$$
E_{t}\left(\pi_{t}^{I}\right)=\left(a_{t}-w_{t}-\varepsilon_{t}\right)+\delta E_{t}\left(\pi_{t+1}^{I}\right)
$$

where $\delta$ is the time discount factor, $a_{t}$ is the incumbent employee's productivity, and

$$
E_{t}\left(\pi_{t+1}^{I}\right)=E_{t}\left[\left(1-\sigma_{t+1}\right)\left(a_{t+1}-w_{t+1}-E_{t}\left(\varepsilon_{t+1} \mid\left(\varepsilon_{t+1}<\nu_{t}^{I}\right)\right)+\delta \pi_{t+2}^{I}\right)-\phi_{t+1} f\right]
$$

$E\left(\varepsilon \mid \varepsilon<\nu_{t}^{I}\right)$ is the expectation of the random term $\varepsilon$, conditional on this shock falling short of the incumbent employee's retention incentive $\nu_{t}^{I}$, which is defined as

$$
\nu_{t}^{I}=a_{t}-w_{t}+\delta E_{t}\left(\pi_{t+1}^{I}\right)+f
$$

i.e. the retention incentive is the difference between the gross expected profit from retaining the employed worker $\left(a_{t}-w_{t}+\delta E_{t}\left(\pi_{t+1}^{I}\right)\right)$ and the expected profit from firing her $(-f)$.

An incumbent worker is fired in period $t$ when the realized value of the random cost $\varepsilon_{t}$ is greater than the incumbent worker employment incentive: $\varepsilon_{t}>\nu_{t}^{I}$. Since the cumulative distribution of $\varepsilon$ is $C_{\varepsilon}\left(\nu_{t}^{I}\right)$, the employed worker's firing rate is

$$
\phi_{t}=1-C_{\varepsilon}\left(\nu_{t}^{I}\right)
$$

\subsubsection{The Job Offer Decision}

The expected present value of profit generated by an entrant, after the random cost $\varepsilon_{t}$ has been observed, is

$$
E_{t}\left(\pi_{t}^{E}\right)=a_{t}-w_{t}-\varepsilon_{t}-h+\delta E_{t}\left(\pi_{t+1}^{I}\right) .
$$

We define the firm's expected job offer incentive $\nu_{t}^{E}$ as the difference between the gross expected profit from a hired worker $\left(a_{t}-w_{t}-h+\delta E_{t}\left(\pi_{t+1}^{I}\right)\right)$ and the profit from not hiring him (i.e. zero):

$$
\nu_{t}^{E}=a_{t}-w_{t}-h+\delta E_{t}\left(\pi_{t+1}^{I}\right)
$$

\footnotetext{
${ }^{11}$ In the first period, profit is $\left(a_{t}-w_{t}-\varepsilon_{t}\right)$; in the second period, the worker is retained with probability $\left(1-\phi_{t}\right)$ and then generates an expected profit of $a_{t}-w_{t}$, and the worker is fired with a probability of $\phi_{t}$ and then generates a firing cost of $f_{t}$; and so on.
} 
A job is offered when $\nu_{t}^{E}>\varepsilon_{t}$. Thus the job offer rate is

$$
\eta_{t}=C_{\varepsilon}\left(\nu_{t}^{E}\right)
$$

\subsection{The Worker's Behavior}

The incumbent worker's expected present value of utility ex post (once the realized value of the disutility shock $e_{t}$ is known) is

$$
E_{t}\left(V_{t}^{N}\right)=w_{t}-e_{t}+\delta E_{t}\left(\left(1-\sigma_{t+1}\right) V_{t+1}^{N}+\sigma_{t+1} V_{t+1}^{U}\right),
$$

where $E_{t}\left(V_{t+1}^{N}\right)$ is the expected present value of utility of the following period (before the realized value of the shock $e_{t}$ is known):

$$
E_{t}\left(V_{t+1}^{N}\right)=E_{t}\left(w_{t}-E\left(e_{t+1} \mid e_{t+1}<\iota_{t+1}\right)+\delta\left(\left(1-\sigma_{t+1}\right) V_{t+1}^{N}+\sigma_{t+1} V_{t+1}^{U}\right)\right) .
$$

The expected present value utility from unemployment is

$$
E_{t}\left(V_{t}^{U}\right)=b_{t}+\delta E_{t}\left(\mu_{t+1} V_{t+1}^{N}+\left(1-\mu_{t+1}\right) V_{t+1}^{U}\right) .
$$

An unemployed's expected "work incentive" $\iota_{t}$ (the incentive for an unemployed to accept work) is the expected difference between the gross ${ }^{12}$ present value from working $E_{t}\left(\tilde{V}_{t}^{N}\right)=$ $w_{t}+\delta E_{t}\left(\left(1-\sigma_{t+1}\right) V_{t+1}^{N}+\sigma_{t+1} V_{t+1}^{U}\right)$ and the present value from not working $E_{t}\left(V_{t}^{U}\right)$ in the current period:

$$
\iota_{t}=E_{t}\left(\tilde{V}_{t}^{N}-V_{t}^{U}\right)
$$

Thus the unemployed accepts a job offer when $e_{t}<E_{t}\left(\tilde{V}_{t}^{N}-V_{t}^{U}\right)$, so that $e_{t}<$ $\iota_{t}$. Consequently, the job acceptance rate is

$$
\alpha_{t}=C_{e}\left(\iota_{t}\right)
$$

The incumbent worker decides to quit his job when the present value of becoming unemployed exceeds the present value of remaining employed $\left(E_{t}\left(\tilde{V}_{t}^{N}\right)-e_{t}<E_{t}\left(V_{t}^{U}\right)\right)$, so that his expected work incentive is lower than the utility cost $e_{t}>E_{t}\left(\tilde{V}_{t}^{N}-V_{t}^{U}\right)=\iota_{t}$. Thus the

\footnotetext{
${ }^{12}$ The employed worker's "gross" expected present value from working is the employed worker's expected present value of utility without taking the utility shock into account.
} 
quit rate is

$$
\chi_{t}=1-C_{e}\left(\iota_{t}\right) .
$$

\subsection{Employment}

As in the previous model, the match probability is

$$
\mu_{t}=\eta_{t} \alpha_{t}
$$

and the separation probability is

$$
\sigma_{t}=\phi_{t}+\chi_{t}-\phi_{t} \chi_{t}
$$

and the associated employment dynamics equation is

$$
n_{t}=\mu_{t}+\left(1-\sigma_{t}-\mu_{t}\right) n_{t-1}
$$

where the employment persistence parameter $\left(1-\sigma_{t}-\mu_{t}\right)$ depends inversely on the match probability $\mu_{t}$ and the separation probability $\sigma_{t}$. An alternative interpretation of the persistence parameter is given by

$$
1-\sigma_{t}-\mu_{t}=\left(1-\phi_{t}\right)\left(1-\chi_{t}\right)-\eta_{t} \alpha_{t}
$$

where $\left(1-\phi_{t}\right)\left(1-\chi_{t}\right)$, the product of the incumbents' retention rate and staying rate, is the incumbents' survival rate. Thus the persistence parameter is the difference between the incumbents' survival rate and the unemployed workers' match probability.

\subsection{Wage Determination}

We now endogenize the real wage through bargaining. The conventional matching models assume that the real wage is the outcome of Nash bargaining, which takes place after the match has been made. This sequence of decisions is conceptually problematic, particularly when match productivities are heterogeneous. Should not the firms' and workers' incentives to match depend on the wage offered? If workers and jobs differ in terms of their productivities, will not a change in the wage lead to a change in the number of matches that are productive? In practice, of course, we don't find workers and firms agreeing to match before the terms of the employment contract have been set.

This difficulty is easy to overlook in the conventional matching models, where matches are generated mechanically through a matching function, all matches generate a bargain- 
ing surplus, and this bargaining surplus is shared by the worker and the firm through the subsequent wage negotiation. But once the matching process is endogenized in terms of the worker's and firm's incentive to match - as is done in our incentive model - the difficulty comes into sharp relief. Then we see that the match probability depends on the firm's job offer rate and the worker's job acceptance rate, and these rates in turn depend on the wage. Similarly, the separation probability depends on the firm's firing rate and the worker's quit rate, and these rates are also wage-dependent. In this context, it is clear that the number of matches made and destroyed per period of time cannot be determined without prior knowledge of the wage.

On this account, we assume here that wage bargaining takes place before the job offer, acceptance, firing and quit decisions are made. Our aim is to formulate a wage determination model that is (i) simple and tractable, (ii) comparable to the wage bargaining process in the conventional matching models (with the exception of the timing issue above) and (iii) able to reproduce the stylized fact that wages are as volatile as productivity. For this purpose, we let the incumbent workers and entrants receive the same wage $w_{t},{ }^{13}$ determined through Nash bargaining between the firm and its median incumbent worker. The median worker faces no risk of dismissal, as he is at the middle of the $\varepsilon$ distribution. These assumptions satisfy the three aims above, because (i) the simplify the analysis by allowing the employment rate to depend on the wage, but not vice versa, (ii) the Nash bargaining between the firm and the median incumbent is comparable to the wage bargaining in the conventional matching models, and (iii) the negotiated wage turns out to be as volatile as productivity.

Needless to say, other models of wage negotiations could be incorporated into our analysis (e.g. individualistic wage bargaining, monopoly union wage setting, separate wage negotiations for incumbents and entrants, etc.), but we do not do so here since they would substantially complicate the model, ${ }^{14}$ without affecting the main points of our analysis, namely, that the matching and separation rates can be determined endogenously through the job offer, job acceptance, firing and quit decisions, and that these decisions are not replicable through a stable matching function.

The wage bargain takes place in each period of analysis. In the current period $t$, under

\footnotetext{
${ }^{13}$ This assumption also implies that an increase in wages leads to a fall in employment. This employment effect can of course also be generated when incumbent workers and entrants have different wages. For example, Lindbeck and Snower (2001) provide a variety of reasons why entrants do not receive their reservation wage and thus a rise in incumbent workers' wages is not met a counterveiling fall in entrant wages, and thus a rise in incumbent workers' wage lead to a fall in employment. In the context of a Markov model, Diaz-Vazquez and Snower (2003) show that incumbent workers' wages are inversely related to aggregate employment even when entrants receive their reservation wages.

${ }^{14}$ Wages would depend on the time path of employment, while employment depends on the time path of wages.
} 
bargaining agreement, the median incumbent worker receives the wage $w_{t}$ incurs effort cost $e^{M}$ and the firm receives the expected profit $\left(a_{t}-w_{t}-\varepsilon^{M}\right)$ in each period $t$. Thus the expected present value of the median incumbent worker's utility $E\left(V_{t}^{M}\right)$ under bargaining agreement is

$$
E_{t}\left(V_{t}^{M}\right)=w_{t}-e^{M}+\delta E_{t}\left(\left(1-\sigma_{t+1}\right) V_{t+1}^{N}+\sigma_{t+1} V_{t+1}^{U}\right) .
$$

The expected present value of firm's returns under bargaining agreement are

$$
E_{t}\left(\Pi_{t}^{M}\right)=\left(a_{t}-w_{t}-\varepsilon^{M}\right)+\delta E_{t}\left(\left(1-\sigma_{t+1}\right) \Pi_{t+1}^{N}-\sigma_{t+1} f\right) .
$$

Under disagreement in bargaining, the incumbent worker's fallback income is $d$, which can be conceived as financial support from family and friends, strike pay out of a union fund, or other forms of support. The firm's fallback profit is $-z$, a constant. Assuming that disagreement in the current period does not affect future returns, the present value of utility under disagreement for the incumbent worker is

$$
E\left(V_{t}^{\prime M}\right)=d+\delta E_{t}\left(\left(1-\sigma_{t+1}\right) V_{t+1}^{N}+\sigma_{t+1} V_{t+1}^{U}\right)
$$

and the present value of profit under disagreement for the firm is

$$
E\left(\Pi_{, t}^{\prime M}\right)=-z+\delta E_{t}\left(\left(1-\sigma_{t+1}\right) \Pi_{t}^{N}-\sigma_{t+1} f\right) .
$$

The incumbent worker's bargaining surplus is

$$
\begin{aligned}
E_{t}\left(V_{t}^{M}\right)-E_{t}\left(V_{t}^{\prime M}\right) & =w_{t}-e^{M}+\delta E_{t}\left(\left(1-\sigma_{t+1}\right) V_{t+1}^{N}+\sigma_{t+1} V_{t+1}^{U}\right) \\
& -d-\delta E_{t}\left(\left(1-\sigma_{t+1}\right) V_{t+1}^{N}+\sigma_{t+1} V_{t+1}^{U}\right) \\
& =w_{t}-d-e^{M}
\end{aligned}
$$

and the firm's surplus is

$$
\begin{aligned}
E_{t}\left(\Pi_{t}^{M}\right)-E_{t}\left(\Pi_{t}^{\prime M}\right) & =\left(a-w_{t}-\varepsilon^{M}\right)+\delta E_{t}\left(\left(1-\sigma_{t+1}\right) \Pi_{t}^{N}-\sigma_{t+1} f_{t+1}\right)- \\
& E_{t}\left(-z+\delta\left(\left(1-\sigma_{t+1}\right) \Pi_{t}^{N}-\sigma_{t+1} f_{t+1}\right)\right) \\
& =a_{t}-w_{t}-\varepsilon^{M}+f_{t}
\end{aligned}
$$

The negotiated wage maximizes the Nash product $(\Lambda)$ :

$$
\Lambda=\left(w_{t}-e^{M}-d\right)^{\gamma}\left(a_{t}-w_{t}+z-\varepsilon^{M}\right)^{1-\gamma} .
$$


Thus the negotiated wage is

$$
w_{t}=\gamma\left(a_{t}+z-\varepsilon^{M}\right)+(1-\gamma)\left(e^{M}+d\right)
$$

where $\gamma$ represents the bargaining strength of the incumbent worker relative to the firm.

\subsection{The Labor Market Equilibrium}

The labor market equilibrium is the solution of the system comprising the following equations:

- Incentives: the incumbent worker retention incentive $\nu_{t}^{I}$ (eq. 23), the job offer incentive $\nu_{t}^{E}$ (eq. 26), the work incentive $\iota_{t}$ (eq. 31).

- Employment decisions: the firing rate $\phi_{t}$ (eq. 24), and the job offer rate $\eta_{t}$ (eq. 27 ).

- Work decisions: the job acceptance rate $\alpha_{t}$ (eq. 32 ) and the quit rate $\chi_{t}$ (eq. 33 ).

- Match and separation probabilities: the match probability $\mu_{t}$ (eq. 34) and the separation probability $\sigma_{t}$ (eq. 35).

- Employment and wage determination: the employment level $N_{t}$ (eq. 36) and the negotiated wage $w_{t}$ (eq. 45$)$.

\section{Calibration}

We now calibrate our incentive model for the US economy. The calibration is done on a monthly basis. The simulation results are aggregated to quarterly frequency to make them comparable to the empirical data, as for example in Shimer (2005). For the discount factor $\delta=\frac{1}{1+r}$ we apply the real interest rate $r=1.04^{1 / 12}-1$. We normalize the average productivity (a) to 1 . As in Hall (2005) and Shimer (2005), we set $b$ by applying a replacement rate of $\beta=40 \%$ of the wage. For simplicity, we set $d=b$. As commonly found in the literature we adopt a bargaining power parameter $\gamma$ of 0.5 .

Vacancy posting costs are usually set to around 30 percent of the quarterly productivity in the conventional matching model calibrations. To make our calibration as comparable as possible to conventional ones, we divide this number by the typical quarterly worker finding rate of 0.7 (see, e.g., Krause and Lubik, 2007 and Den Haan et al., 2000) to obtain the hiring costs, $h$. This gives us a value of 43 percent of the quarterly productivity or roughly 130 percent of the monthly productivity. 
The literature does not provide reliable direct estimates of the magnitude of US firing costs. Thus we assess these costs indirectly. For this purpose, note that Belot et al. (2007) provide index measures of employment protection for regular jobs in the US and UK, and that Bentolila and Bertola (1990) provide estimates of the average magnitude of UK firing costs on a yearly basis. ${ }^{15}$ Assuming that the index measures of employment protection are proportional to the estimates of the magnitude of firing costs, we multiply the magnitude of the UK firing costs by the ratio of the US to the UK employment protection indeces to derive a rough estimate of the magnitude of US firing costs. Accordingly, the magnitude of monthly US firing costs, relative to productivity, is 0.08 . The same exercise based on other industrialized countries (France, Germany and Italy), however, yields higher estimates of US firing costs. Thus we choose a value of 0.1 for our baseline calibration, but provide a robustness analysis for other values in Appendix B. ${ }^{16}$ For simplicity, we set the firm's fallback profit $-z$ equal to $-f .{ }^{17}$

We assume that the random profitability term $\varepsilon$ and the utility shock $e$ have cumulative distributions given by logistic functions with scale factors $s_{\varepsilon}$ and $s_{e}$ and expected values $\bar{\varepsilon}$ and $\bar{e}$, respectively. ${ }^{18}$ We calibrate our model such that it replicates the stylized fact that a $1 \%$ increase of productivity is associated with about a $1 \%$ increase of wage. ${ }^{19}$ This is achieved by setting $\bar{e}=0.19$. Thereby our calibration excludes the possibility that our results are driven by real wage rigidity. We assign values to the remaining free parameters of the model $\left(\bar{\varepsilon}, s_{e}, s_{\varepsilon}\right)$ so as to replicate the following steady state values (summarized in Table 1): ${ }^{20}$ The match probability $\mu$, which is the probability for a worker to find a new job within one period, is calibrated to $45 \%^{21}$, as in Shimer (2005) and Hagedorn and Manvoskii (2008). The unemployment rate $u$ is calibrated to $12 \% .{ }^{22}$ According to our employment dynamics equation (12) steady state unemployment is $u=\frac{\mu}{\mu+\sigma}$ which implies a separation rate of $6.14 \%$. Based on Hall (2005), who shows that fires and quits have approximately the same share in separation, we assume firings to account for $50 \%$ of the separations, namely $\phi=3.1 \%$. Eq. (35) then yields the quit rate of $\chi=3.2 \%$. Since $\alpha$ is equal to $1-\chi$, the job

\footnotetext{
${ }^{15}$ We take averages over the time periods provided by these authors.

${ }^{16}$ Specifically, we provide simulation results for firing costs calculated relative to the UK, $f=0.08$, and as an upper bound we choose $f=0.2$.

${ }^{17}$ Here we implicitly assume that during disagreement the incumbent worker imposes the maximal cost on the firm short of inducing dismissal.

${ }^{18}$ The cumulative logistic distribution is very close to the cumulative normal distribution.

${ }^{19}$ See Hornstein et al. (2005).

${ }^{20}$ Specifically, the three parameters set $\alpha, \eta$, and $\phi$. From these latter flow rates, the remaining rates can be derived.

${ }^{21}$ Note: In our model the worker finding rate (i.e., the probability of a firm to find a new worker) and the job finding rate (i.e., the probability of a worker to find a new) are the same.

${ }^{22}$ This value also considers potential participants in the labor market such as discouraged workers and workers loosely attached to the labor force, see Krause and Lubik (2007) and den Haan et al. (2000).
} 
acceptance rate is set at $96.8 \%$. Recalling that $\mu=\alpha \eta$, we find that the resulting job offer rate $\eta$ is $46.5 \%$.

We normalize the autocorrelation $\left(\rho_{a}\right)$ of the aggregate productivity shock and normalize the standard error such that we obtain the empirical values for the autocorrelation and the volatility of productivity in the model simulation below. Table 2 summarizes our calibrated parameter values.

\begin{tabular}{|l|l|l|}
\hline Variable & In Words & Steady State Value \\
\hline$u$ & unemployment rate & 0.120 \\
\hline$\mu$ & match probability & 0.450 \\
\hline$\eta$ & hiring/job offer rate & 0.465 \\
\hline$\sigma$ & separation rate & 0.061 \\
\hline$\phi$ & firing rate & 0.031 \\
\hline$\chi=1-\alpha$ & job quit rate & 0.032 \\
\hline \multicolumn{3}{|c|}{ Table 1: Steady State Values }
\end{tabular}

\begin{tabular}{|l|l|l|}
\hline Parameter & In Words & Value \\
\hline$a$ & productivity & 1 \\
\hline$\beta$ & replacement rate $\frac{b}{w}, \frac{d}{w}$ & 0.4 \\
\hline$f$ & firing cost & 1.3 \\
\hline$h$ & hiring cost & 0.1 \\
\hline$\gamma$ & workers' bargaining strength & 0.5 \\
\hline$r$ & discount factor & 0.997 \\
\hline$-z$ & firm's fallback profit & -0.1 \\
\hline $\bar{e}$ & average value of leisure & 0.17 \\
\hline $\bar{\varepsilon}$ & average operating costs & 0.465 \\
\hline$s_{\varepsilon}$ & scale factor of the cumulative distribution of $\varepsilon_{t}$ & 0.390 \\
\hline$s_{e}$ & scale factor of the cumulative distribution of $e_{t}$ & 0.078 \\
\hline$\rho_{a}$ & autocorrelation of the aggregate productivity shock & 0.975 \\
\hline$\varpi_{a}$ & standard error of the aggregate productivity shock & 0.007 \\
\hline
\end{tabular}

Table 2: Parameter Values (Rounded to the Third Decimal)

\section{Description of Results}

\subsection{Labor Market Volatilies}

Costain and Reiter (2007) and Shimer (2005) point out that the conventional calibration of the matching model is unable to replicate the volatility of the job finding rate, the unem- 
ployment rate, and other labor market variables in response to productivity shocks. Table 3 shows that the empirical volatilities for the United States (from 1951-2003, HP filtered data with smoothing parameter 10000, as calculated by Shimer) are far greater than the corresponding volatilities in response to productivity shocks, as generated by the simulation of the conventional matching model (in its standard calibration, as calculated by Shimer).

\begin{tabular}{|l|l|l|l|l|}
\hline & U. Rate & Match. Rate & Sep. Rate & Product. \\
\hline Empirical Volatilities by Shimer (2005), from 1951-2003 \\
\hline Standard deviation & 0.19 & 0.12 & 0.08 & 0.02 \\
\hline Relative to productivity & $\mathbf{9 . 5}$ & $\mathbf{5 . 9}$ & $\mathbf{3 . 8}$ & $\mathbf{1}$ \\
\hline Quarterly autocorrelation & 0.94 & 0.91 & 0.73 & 0.88 \\
\hline \multicolumn{5}{|l|}{} \\
\hline
\end{tabular}

Table 3: Empirical Volatilities and Volatilities generated by the Search and Matching Model from Shimer (2005).

To compare our model with the conventional matching theory, we use our baseline calibration (with robustness checks in the Appendix B) to simulate our model for 200 quarters (i.e. 600 months). We repeat this exercise 10,000 times and report the average of the macroeconomic volatilities (HP filtered simulated data with smoothing parameter 10000) in Table 4 .

\begin{tabular}{|l|l|l|l|l|}
\hline & U. Rate & Match. Rate & Sep. Rate & Product. \\
\hline Standard Calibration \\
\hline Standard deviation & 0.19 & 0.13 & 0.07 & 0.02 \\
\hline Relative to productivity & $\mathbf{8 . 8}$ & $\mathbf{6}$ & $\mathbf{3 . 5}$ & $\mathbf{1}$ \\
\hline Quarterly autocorrelation & 0.90 & 0.88 & 0.88 & 0.88 \\
\hline
\end{tabular}

Table 4: Volatilities generated by the Incentive Model of Matching

The differences between our model and the conventional matching model are striking. Our model can generate the high macroeconomic volatilities found in the data. Our results are all the more remarkable, as we do not neither have to resort to Hall's (2005) real wage rigidity assumption nor to Hagedorn and Manovskii's (2008) small surplus calibration.

Specifically, the more rigid the wage in the conventional matching model (Hall, 2005), the greater the share of productivity variations that is captured by the firm and thus the greater 
the volatility of vacancies. However, there is evidence against the rigid-wage hypothesis both from the microeconometric and the macro perspective. Haefke et al. (2008) show that wages for newly created jobs (i.e., those modeled in the matching model) are completely flexible on a microeconomic level. Hornstein et al. (2005) point out that wages are roughly as volatile as the labor productivity on a macroeconomic level. By contrast, our model generates high labor market volatilities, even though it replicates the stylized fact that wages are as volatile as productivity.

Hagedorn and Manovskii (2008) choose a small-surplus calibration to resolve the volatility puzzle of the matching model. Under this calibration, aggregate profits are only a very small share of the overall production in the steady state, so that a positive productivity shock sharply increases the relative profits. This gives a large incentive to firms to post more vacancies (due to the free entry condition). Consequently all labor market variables become volatile. This type of calibration has several shortcomings. Besides the unrealistically low profit share, the utility value of unemployment is extremely high and workers' bargaining power is very low in the calibration. Therefore workers are almost indifferent between working and not working. We do not need to rely on any of these mechanisms in our calibration. As noted, we assume that worker's bargaining power is 50 percent. The labor income divided by overall production is roughly 80 percent in our model. Furthermore, the average worker's disutility of labor and unemployment benefits make up only 80 percent of the current wage. As a consequence, the average worker is not indifferent between unemployment and employment.

\subsection{Correlations}

Our model features several additional advantages compared to the conventional matching framework. Krause and Lubik (2007) show that the matching framework with endogenous job destruction and flexible wages cannot generate a strong negative correlation between the job finding rate and the unemployment. In all of our model simulations, the correlation between these two variables is very strongly negative, in magnitude between -0.95 and -0.99 , i.e., slightly higher than in the US data (-0.95, see Shimer, 2005).

Further, Krause and Lubik (2007) show that the matching model with endogenous job destruction and flexible wages cannot account for the negative correlation between job destruction and job creation. In our model, the correlation between these two variables is always negative and close to $-1 .^{23}$

\footnotetext{
${ }^{23}$ The job finding rate and the job destruction rate are both driven by the same underlying shock, resulting in this strong negative correlation. We could get a lower correlation if we introduced another shock to drive a wedge between the shocks underlying job destruction and those underlying job creation. However, for
} 


\section{Conclusion}

This paper has presented a theory of labor market matching that does not rely on a matching function. Whereas the matching function is meant to encapsulate "heterogeneities, frictions and information imperfections," 24 we have presented models that depict these phenomena explicitly within a simple analytical framework. In this context, we have shown that the matching function is not stable with respect to conventional labor market policies and various standard macroeconomic shocks. Thus the matching function is vulnerable to the Lucas critique, and its use for policy analysis and prediction becomes problematic.

The general intuition is straightforward. Although it is often claimed that the matching function is analogous to a production function, an important difference stands out. A firm's production function captures the portfolio of available technologies, and these are often invariant with respect to many government policies and macroeconomic variations. By contrast, a matching function summarizes the upshot of the many individual decisions by firms and workers, responding to their individual incentives to offer, accept, quit and destroy jobs, and these incentives are in general affected by policies and macro shocks. In this respect, the matching function appears to face difficulty analogous to the adaptive expectations hypothesis, which sought to predict expectations without reference to the actual stochastic processes in the economy. Just as predictable changes in policies and and macroeconomic variables could be expected to influence agents' expectations, so these changes can also be expected to influence agents' incentives to generate labor market matches.

Our incentive theory provides a different view of the matching process than that presented by a matching function. Whereas the matching function depicts matches as the output of a "matching technology" that mechanically pairs unemployed workers and vacant firms, the incentive theory explains the matching probability in terms of the firm's job offer incentive and the worker's job acceptance incentive. Similarly, the separation probability is explained in terms of the firm's firing incentive and the worker's quit incentive. These incentives depend on all the parameters of the model, including policy and macro parameters.

To keep our formal analysis as simple as possible, we have made some radically simplifying assumptions, such as those concerning wage determination, the depiction of heterogeneities in terms of only two additive shocks $\varepsilon$ and $e$, and the depiction of adjustment costs in terms of only two additive costs $h$ and $f$. Whereas these simplifying assumptions naturally affect the quantitative predictions of our model, they are not essential to basic idea that motivates this paper: namely, that the matching and separation probabilities can be understood in

simplicity we do not choose this option.

${ }^{24}$ Pissarides, 2000, p. 3. 
terms of job offer, job acceptance, firing, and quit probabilities, which may be derived from the optimizing decisions of firms and workers. This is the central contribution of this paper, obviating the need for a matching function. These optimizing decisions - in the presence of heterogeneous workers and jobs, as well as costs of adjustment - explain why some job-seeking workers remain unemployed and some vacant jobs remain unfilled.

Needless to say, the incentive models presented above are merely a first step towards a choice-theoretic understanding of the matching process. Much research remains to be done. Although relaxing our simplifying assumptions regarding wage determination, heterogeneities and adjustment costs will not affect the basic idea above, it will help us refine the quantitative predictive properties of the incentive model.

Nevertheless, we have shown that even on the basis of our radically simplifying assumptions, our calibrated incentive model can account for various important empirical regularities that have eluded the conventional matching models. In particular, our model comes close to generating the empirically observed volatilities of the unemployment rate, the job finding rate and the separation rate. Furthermore, our model can also account for the observed strong negative correlations between the job finding rate and the unemployment rate, and between job creation and job destruction.

\section{References}

[1] Bentolila, Samuel, and Guiseppe Bertola. 1990. "Firing Costs and Labour Demand: How Bad Is Eurosclerosis?" Review of Economic Studies, 57(3): 381-402.

[2] Blanchard, Olivier J., and Peter A. Diamond. 1989. "The Beveridge Curve." Brookings Papers on Economic Activity, 20(1): 1-76.

[3] Costain, James S., and Michael Reiter. 2007. "Business Cycles, Unemployment Insurance, and the Calibration of Matching Models." Journal of Economic Dynamics and Control, 32(4): 1120-1155.

[4] Diaz-Vazquez, Pilar, and Dennis J. Snower. 2003. "Can Insider Power Affect Employment?" German Economic Review, 4(2) 139-150.

[5] Fahr, René, and Uwe Sunde. 2001. "Disaggregate Matching Functions." IZA Discussion Papers 335.

[6] Fahr, René, and Uwe Sunde. 2004. "Occupational Job Creation: Patterns and Implications." Oxford Economic Papers, 56(3): 407-435. 
[7] Fujita, Shigeru, and Garey Ramey. 2009. "The Cyclicality of Separation and Job Finding Rates." International Economic Review, 50(2): 415-430.

[8] den Haan, Wouter J., Garey Ramey, and Joel Watson. 2000. "Job Destruction and Propagation of Shocks." American Economic Review, 90(3): 482-498.

[9] Haefke, Christian, Markus Sonntag, and Thijs van Rens. 2008. "Wage Rigidity and Job Creation." IZA Working Paper 3714.

[10] Hagedorn, Marcus, and Iourii Manovskii. 2008. "The Cyclical Behavior of Equilibrium Unemployment and Vacancies Revisited." American Economic Review, 98(4): 16921706.

[11] Hall, Robert E. 1977. "An Aspect of the Economic Role of Unemployment." In Microeconomic Foundations of Macroeconomics, ed. Geoffrey C. Harcourt, 354-72, London: Macmillan.

[12] Hall, Robert E. 2005. "Employment Fluctuations with Equilibrium Wage Stickiness." American Economic Review, 95(1): 50-65.

[13] Hall, Robert E. 2006. "Job Loss, Job Finding and Unemployment in the US Economy over the Past Fifty Years." NBER Maroeconomics Annual, 20: 101-137.

[14] Hornstein, Andreas, Per Krussell, and Giovanni L. Violante. 2005. "Unemployment and Vacancy Fluctuations in the Matching Model: Inspecting the Mechanism." Federal Reserve Bank of Richmond Economic Quarterly 91(3): 19-51.

[15] Krause, Michael U., and Thomas A. Lubik. 2007. "The (Ir)relevance of Real Wage Rigidity in the New Keynesian Model with Search Frictions." Journal of Monetary Economics, 54(3): 706-727.

[16] Lagos, Ricardo. 2000. "An Alternative Approach to Search Frictions." Journal of Political Economy, 108(5): 851-873.

[17] Lindbeck, Assar, and Dennis J. Snower. 2001. "Insiders versus Outsiders." Journal of Economic Perspectives, 15(1): 165-188.

[18] Mortensen, Dale T., and Christopher A. Pissarides (1994), "Job Creation and Job Destruction in the Theory of Unemployment." Review of Economic Studies, 61(3), 397415 . 
[19] Petrongolo, Barbara, and Christopher Pissarides. 2001. "Looking into the Black Box: A Survey of the Matching Function." Journal of Economic Literature, 39(2): 390-431.

[20] Pissarides, Christopher A. 2000. Equilibrium Unemployment Theory. Cambridge, MA: MIT Press.

[21] Shimer, Robert. 2005. "The Cyclical Behavior of Equilibrium Unemployment and Vacancies." American Economic Review, 95(1): 25-49.

[22] Shimer, Robert. 2007. "Mismatch." American Economic Review, 97(4): 1074-1101.

\section{A Appendix: Vacancies}

Suppose that by posting vacancies, the firm can reduce its subsequent screening costs, which are a component of hiring costs. Specifically, let the vacancy posting cost be $\gamma$ per vacancy and let the hiring cost be $h=\frac{1}{\alpha} v^{-\alpha}$, where $v$ is the number of vacancies posted and $\alpha$ is a positive constant. Assuming that the firm makes its vacancy posting decision before the realization of $\varepsilon$ is known, the firm sets the number of vacancies to maximize its expected profit $E(\pi)=\mu(a-w-h-E(\varepsilon))-\gamma v$. Since $E(\varepsilon)=0$, the profit-maximizing number of vacancies is $v=\left(\frac{\mu}{\gamma}\right)^{\frac{1}{1 * \alpha}}$.

\section{B Appendix: Robustness}

Table 5 provides a robustness analysis of the labor market volatilities implied by our model for values of the firing cost $f=0.08$ and $f=0.20$.

\begin{tabular}{|c|c|c|c|c|}
\hline & U. Rate & Match. Rate & Sep. Rate & Product. \\
\hline \multicolumn{5}{|l|}{ Volatilities for $f=0.08$} \\
\hline Standard deviation & 0.23 & 0.14 & 0.09 & 0.02 \\
\hline Relative to productivity & 10.7 & 6.6 & 4.4 & 1 \\
\hline Quarterly autocorrelation & 0.90 & 0.88 & 0.88 & 0.88 \\
\hline \multicolumn{5}{|l|}{ Volatilities for $f=0.2$} \\
\hline Standard deviation & 0.11 & 0.09 & 0.03 & 0.02 \\
\hline Relative to productivity & 5.2 & 4.5 & 1.5 & 1 \\
\hline Quarterly autocorrelation & 0.91 & 0.88 & 0.88 & 0.88 \\
\hline
\end{tabular}

Table 5: Robustness Analysis of the Labor Market Volatilities Implied by our Model for Values of the Firing Cost $f=0.08$ and $f=0.20$. 